\title{
Spousal Concordance for Alcohol Dependence: Evidence for Assortative Mating or Spousal Interaction Effects?
}

\author{
Julia D. Grant, Andrew C. Heath, Kathleen K. Bucholz, Pamela A.F. Madden, \\ Arpana Agrawal, Dixie J. Statham, and Nicholas G. Martin
}

\begin{abstract}
Background: Alcohol dependence (AD) is among the most common psychiatric disorders, and impacts the health and well-being of problem drinkers, their family members, and society as a whole. Although previous research has consistently indicated that genetic factors contribute to variance in risk for $\mathrm{AD}$, little attention has been paid to nonrandom mating for $\mathrm{AD}$. When assortative mating occurs for a heritable trait, spouses are genetically correlated and offspring are at increased risk of receiving high-risk genes from both parents. The primary goal of the present analyses is to test hypotheses about the source(s) and magnitude of spousal associations for AD using a twin-spouse design.

Methods: DSM-IV AD (without the clustering criterion) was assessed via telephone interview for 5,974 twin members of an older cohort of the Australian Twin Register (born 1902-1964) and 3,814 spouses of the twins. Quantitative genetic modeling was used to determine the extent to which variability in risk for $\mathrm{AD}$ was influenced by genetic factors, the extent of spousal association for $\mathrm{AD}$, and whether the association was attributable to assortative mating, reciprocal spousal interaction, or both processes.

Results: Genetic factors explained $49 \%$ of the variance in risk for AD. There was no evidence of gender differences in the spousal interaction effect, the degree of rater bias, or the association between the twin's report of spouse AD and the spouse's AD phenotype. Either the assortative mating parameter or the spousal interaction parameter could be removed from the model without a significant decrement in fit, but both could not be dropped simultaneously, suggesting a lack of power to differentiate between these 2 causes of spousal correlation. When both effects were included in the model, the spousal correlation was 0.29 , the assortative mating coefficient was 0.45 (i.e., "like marries like"), and the reciprocal spousal interaction coefficient was - 0.10 (i.e., after controlling for assortative mating, the additional impact of spousal interactions is slightly protective).

Conclusions: These analyses provide evidence of significant spousal associations for AD, with assortative mating increasing spouse similarity and spousal interaction effects decreasing it after controlling for assortative mating. Although the genetic impact is modest, assortative mating results in an increased proportion of offspring exposed to 2 alcoholic parents and the associated detrimental environmental sequelae, and increases the likelihood of offspring inheriting high-risk genes from both parents.
\end{abstract}

Key Words: Alcohol Dependence, Nonrandom, Mating, Heritability, Twins.

A LCOHOL DEPENDENCE (AD), which is among the most common psychiatric disorders in the general population, has a significant impact on public health. Data collected recently as part of the National Epidemiologic Survey on Alcohol and Related Conditions (NESARC) suggest that the lifetime prevalence of any alcohol use disorder in the United States is 30.3\% (42.0\% for men and $19.5 \%$ for women; Compton et al., 2005),

From the Department of Psychiatry, Washington University School of Medicine, St. Louis, Missouri (JDG, ACH, KKB, PAFM, AA); and the Queensland Institute of Medical Research, Brisbane, Australia (DJS, NGM).

Received for publication April 1, 2006; accepted January 7, 2007.

Sources of support: AA11998, AA07535, AA00728, AA10249.

Reprint requests: Julia D. Grant, PhD, Department of Psychiatry, Washington University School of Medicine, Campus Box 8134, St. Louis, MO 63110; Fax: 314286 2243; E-mail: grantj@msnotes.wustl.edu

Copyright (C) 2007 by the Research Society on Alcoholism.

DOI: $10.1111 /$ j.1530-0277.2007.00356.x with about $41 \%$ of those individuals meeting AD criteria. Assessments of past-year AD in NESARC indicated that the 12 -month prevalence of AD was 3.81\% (Grant et al., 2004b). Comparison of the 12-month prevalence of AD in NESARC (2001-2002) with the National Longitudinal Alcohol Epidemiologic Survey (NLAES, 1991-1992) suggests that the past-year prevalence decreased slightly during that period (from 6.33 to $5.42 \%$ for men and from 2.58 to $2.32 \%$ for women; Grant et al., 2004a). This comparison assumes that the sampling, assessments, and diagnostic algorithms are the same for the 2 studies. The NLAES and NESARC findings are in keeping with those observed by Caetano and Cunradi (2002) in their review of research on AD.

Given the relatively high prevalence of alcohol problems, it is not surprising that "alcohol ranks high as a cause of disease burden ... [and] ... imposes a high economic cost on society" (World Health Organization, 2001, p. 32). The World Health Organization (2003) indicated that alcohol 
use disorders accounted for $1.4 \%$ of the disease burden throughout the world. In addition to the costs associated with alcohol-related illnesses, AD contributes substantially to numerous difficulties in social, financial, and legal realms. Caetano and Cunradi (2002) noted that although alcohol-dependent individuals account for only about $6 \%$ of the U.S. population in a given year, these individuals account for approximately $50 \%$ of alcohol-related problems within a year.

Variation in alcohol dependence risk has a strong familial component (see Cotton, 1979; McGue, 1994; Merikangas, 1990 for reviews). Family history research has consistently indicated that rates of alcoholism are higher among first-degree relatives of alcoholic individuals than among first-degree relatives of nonalcoholic individuals. In her review of familial influences on variability in risk for alcoholism, Cotton (1979) observed a roughly 5-fold increase in risk of alcoholism among parents of probands who were alcoholic individuals compared with parents of probands who were not psychiatric patients. Most of the studies reviewed by Cotton were based on clinical and/or hospitalized samples, which could result in risk ratios that differ from those observed with nonclinical populations. Multiple recent studies have reported risk ratios closer to 2 for first-degree relatives of alcoholic individuals compared with those of nonalcoholic individuals (e.g., Dawson and Grant, 1998; Jacob et al., 2003; Nurnberger et al., 2004).

Risk to relatives of an alcohol-dependent individual could stem from genetic and/or environmental factors. Twin and adoption studies of AD, which can tease apart genetic and environmental contributions, have consistently suggested moderate heritability for men (see Heath et al., 1997b; McGue, 1994; Prescott, 2001 for reviews), with estimates of genetic influences on variability in risk for $\mathrm{AD}$ generally between 40 and $60 \%$. For women, estimates of the heritability of AD have been less consistent (see Heath et al., 1997b; McGue, 1994; Prescott, 2001 for reviews). Some studies have indicated little or no genetic influence on variability in risk for AD among women (e.g., McGue, 1994; McGue et al., 1992), whereas others have provided heritability estimates of 50 to $64 \%$ (Heath et al., 1997a; Kendler et al., 1992). A related issue, whether the genetic influences on variability in risk for AD are the same for men and women, is also still a matter of debate. Although Heath et al. (1997a) found that the heritability estimates for men and women could be equated, suggesting that there are no gender differences, other researchers have found evidence that there is incomplete genetic overlap, or a different magnitude of genetic influence on variability in risk for AD among men and women (Jang et al., 1997; Prescott, 2001, 2002; Prescott and Kendler, 2000; Prescott et al., 1999). The issue of heritability equivalence is particularly important in light of work by Prescott and Kendler (2000) and Prescott et al., (1999) suggesting that the discrepancy regarding heritabil- ity equivalence for men and women may be associated with sample ascertainment: whereas epidemiological samples yield comparable heritability estimates across gender, clinical samples tend to indicate higher heritability for men than women. It should be noted that the heritable component of variability in risk for $\mathrm{AD}$ is attributable to the effects of multiple genes, with each gene explaining only a very small proportion of variance in risk, as is likely to be true for most disorders (Ioannidis et al., 2006).

One factor that may contribute to variability in alcohol consumption and AD risk is spousal influence. Alcohol consumption patterns (frequency, quantity, and even misuse/abuse/dependence) are likely to be correlated among spouses, and given that most people spend a significant portion of their adult lives married, the spousal relationship has the potential to shape development across the lifespan. Assortative mating (AM) is a process of nonrandom mating in which individuals select spouses based on characteristics that they and their partner share. In the general population, AM is commonly described as "like marries like" and "opposites attract," phrases which reflect the types of AM. "Like marries like" refers to positive assortative mating, in which individuals seek spouses with whom they share certain traits. In contrast, "opposites attract" refers to negative assortative mating, in which individuals seek spouses with whom they differ on certain traits. The importance of including AM, and methods of assessing AM effects, have been discussed in the literature for many decades and remain a topic of interest (e.g., Eaves, 1979; Eaves et al., 1984, 1989; Fisher, 1918; Heath, 1987; Heath and Eaves, 1985; Wright, 1921).

Association between spouses may also stem in part from social processes such as social homogamy and/or reciprocal spousal interactions (Vanyukov et al., 1996). With social homogamy, similarities between spouses stem from their correlated environments. With reciprocal spousal interaction (also referred to as contagion), the behavior of 1 individual directly influences the behavior of his/her spouse. As with AM, spousal interactions (SI) can be either positive or negative. With positive SIs, an individual's behavior increases the likelihood that his/her spouse will exhibit the same behavior (e.g., if an individual has $\mathrm{AD}$, there is an increased likelihood that his/her spouse will develop AD). With negative SIs, an individual's behavior decreases the likelihood that the spouse will exhibit that behavior (e.g., the spouse of an individual with AD might reduce or quit drinking alcohol).

Evidence of significant positive nonrandom mating has consistently been observed for risk of AD (Agrawal et al., 2006; Hall et al., 1983, Kendler et al., 1994a; Maes et al., 1998; Stallings et al., 1997) as well as for risk of other substance use disorders (Hopfer et al., 2003; Sakai et al., 2004; Vink et al., 2003). Early analyses suggested that AM was a more appropriate explanation of spousal correlations than was social homogamy (Hall et al., 1983). Multivariate 
studies by Stallings et al. (1997) and Maes et al. (1998) both found significant $\mathrm{AM}$ for $\mathrm{AD}$, with evidence for cross assortment between AD and other psychiatric disorders. In addition, Maes et al. tested other forms of spousal association, finding that only a small portion of the spousal resemblance was attributable to social homogamy, and that for an older sample $(M=35$ years of marriage) SI could not be excluded as diagnoses often developed after marriage (although its influence seemed to be unlikely for their younger sample, $M=15$ years of marriage). Kendler et al. (1994a) obtained significant AM estimates for 2 broad definitions of $\mathrm{AD}$, but not a narrow one; they did not assess other forms of spousal association. Agrawal et al. (2006) found evidence of significant primary AM for regular alcohol use and DSM-IV AD in a sample of female twins and their spouses. Once the effects of AM were controlled for, they found evidence of an additional protective reciprocal spousal interaction effect for regular alcohol use, but not for AD.

Assortative mating is typically viewed as a phenotypic process whereby individuals seek partners (either consciously or unconsciously) with specific observable characteristics. However, for heritable behaviors, phenotypic AM results in spouses who are genetically correlated and in offspring (i.e., siblings) who share (on average) more than $50 \%$ of their segregating genes (Bulmer, 1980; Fisher, 1918; Heath et al., 1987; Reynolds et al., 1996). Therefore, if individuals at increased genetic risk of developing AD marry individuals who are also at increased genetic risk, then any children from this mating will be more likely to receive risk alleles from both parents rather than from 1 parent only, and there is an increased likelihood that the children will have 2 psychiatrically impaired parents, which can yield its own detrimental environmental and genotype $\times$ environment sequelae. The nonzero genetic correlation between spouses and the increase in the genetic correlation between siblings would likely be quite modest, given that the change is dependent on both the heritability of the trait and the degree of marital assortment. Over time, secular changes in AM can produce a relative increase in the proportion of variability attributable to genetic factors, and thereby change (i.e., increase, assuming positive AM) the prevalence of AD. In contrast to AM, spousal interaction processes occur solely at the phenotypic level. Thus, parental generation spousal interaction will have no impact on the genetic similarity of offspring, but because it will impact the environment for all members of a family, it represents an important environmental influence on offspring.

Given the significant genetic contribution to $\mathrm{AD}$, the evidence of modest nonrandom mating for $\mathrm{AD}$, and the fact that AM for a heritable trait results in spouses who are genetically correlated and offspring who are at increased risk of receiving high risk genes from both parents, further examination of nonrandom mating for $\mathrm{AD}$ is warranted. In addition, because previous research has generally not considered AM and SI in tandem, we do not know which process is in effect. The primary goal of the present analysis is to extend the literature on spousal correlations for AD by assessing AM and SI simultaneously using a twin/spouse design, a method that has been previously noted to be informative for testing hypotheses about spouse/partner (or peer) selection versus reciprocal influences (Coventry and Keller, 2005; Heath, 1987; Heath et al., 1985; Madden et al., 2002; Maes et al., 1998; Sakai et al., 2004; Truett et al., 1994).

\section{MATERIALS AND METHODS}

\section{Sample}

The present analyses are based on a sample of adult twin pairs from the Australian Twin Register and their spouses. The volunteer register was formed in 1978 to 1979 and is maintained by the Australian National Health and Medical Research Council. In 1980 to 1981 , 5,967 twin pairs aged 18 and older were sent a mailed questionnaire assessing personality, alcohol consumption, and other health-related habits; both members of 3,808 pairs and an additional 567 individual twins returned the questionnaire $(64 \%$ pairwise response rate; $69 \%$ individual response rate). In 1988 to 1989, a follow-up questionnaire was sent to the complete pairs who participated in the earlier survey, with both members of 2,997 pairs and an additional 335 individual twins responding (79\% pairwise follow-up response rate; $83 \%$ individual follow-up response rate). In 1992 to 1993, telephone diagnostic data were collected from 5,995 twins, with both members of 2,721 pairs and an additional 563 individual members of twin pairs participating. The twin samples are described in more detail elsewhere: "1981 survey" (Jardine and Martin, 1984), "1989 survey" (Heath and Martin, 1994; Heath et al., 1994, 1997a). Identical twin pairs and females are somewhat overrepresented in this sample, as is typically the case with volunteer twin samples. However, the sample represents a broad spectrum of sociodemographic groups and has been found to be broadly representative of the Australian population (Heath et al., 1997a). The 5,974 individuals (2,702 pairs, 570 individuals; 3,894 females, 2,080 males) who participated in the 1992 to 1993 interview and had data for AD formed the basic core of the present analyses.

Between 1994 and 1997, spouses or partners of the twins were recruited for a telephone diagnostic interview. "Partner" data were collected in lieu of spouse data if the twin had lived with the partner "as though married" for at least 6 months; $3.5 \%$ of the twins reported on a partner instead of a spouse, and $1.9 \%$ of the "spouses" interviewed were actually nonmarital partners. The spouse/partner data will be referred to as "spouse" data from this point on. To complete the interview, 2 levels of consent were required: permission from the twin to contact his/her spouse, and agreement from the spouse to complete an interview. A total of 3,846 spouses were interviewed, with 3,814 (1,430 females, 2,384 males) having useable data for the present analyses. Additional data based on the twin's 1992 to 1993 report of his/her spouse's history of alcohol problems were available for 5,365 spouses $(1,835$ female spouses of male twins, 3,530 male spouses of female twins). Care was taken to ensure that the spouse the twin reported on was the same spouse interviewed; if there was any question as to whether the same individual was the spouse, only the interview data were used (in only eight cases were there interview data for the spouse without an accompanying twin report of the spouse's history of alcohol problems). All heterosexual spouse pairs were included, regardless of whether or not they had children $(87 \%$ of twins and $93 \%$ of spouses reported having at least 1 biological child). For the present analyses, spouse data were 
Table 1. Socio-Demographic Characteristics of Australian Twin Pairs and Their Spouses

\begin{tabular}{|c|c|c|c|c|c|c|c|c|c|c|}
\hline \multirow[b]{3}{*}{$n$} & \multicolumn{2}{|c|}{$\begin{array}{c}\text { All twins } \\
\text { interviewed }^{\mathrm{a}}\end{array}$} & \multicolumn{2}{|c|}{$\begin{array}{l}\text { Twins with no } \\
\text { spouse data }\end{array}$} & \multicolumn{2}{|c|}{$\begin{array}{l}\text { Twins with only } \\
\text { twin report on } \\
\text { spouse }\end{array}$} & \multicolumn{2}{|c|}{$\begin{array}{c}\text { Twins with } \\
\text { spouse interview }^{\text {b }}\end{array}$} & \multicolumn{2}{|c|}{$\begin{array}{c}\text { Spouses } \\
\text { interviewed }^{\mathrm{b}, \mathrm{c}}\end{array}$} \\
\hline & Female & Male & Female & Male & Female & Male & Female & Male & Female & Male \\
\hline & 3,894 & 2,080 & 371 & 247 & 1,143 & 408 & 2,380 & 1,425 & 1,430 & 2,384 \\
\hline Mean age at interview (range) & $\begin{array}{c}44.7 \\
(27-90)\end{array}$ & $\begin{array}{c}42.7 \\
(28-89)\end{array}$ & $\begin{array}{c}39.8 \\
(28-89)\end{array}$ & $\begin{array}{c}36.4 \\
(28-71)\end{array}$ & $\begin{array}{c}50.0 \\
(28-90)\end{array}$ & $\begin{array}{c}45.6 \\
(28-89)\end{array}$ & $\begin{array}{c}42.9 \\
(27-77)\end{array}$ & $\begin{array}{c}42.9 \\
(28-84)\end{array}$ & $\begin{array}{c}43.5 \\
(19-88)\end{array}$ & $\begin{array}{c}48.5 \\
(26-90)\end{array}$ \\
\hline \multicolumn{11}{|l|}{ Marital status (\%) } \\
\hline Married & 73.2 & 76.4 & 2.2 & 1.6 & 57.1 & 66.4 & 92.0 & 92.3 & 94.0 & 94.1 \\
\hline Sep./Div./Wid. & 15.2 & 7.7 & 2.4 & 2.0 & 38.7 & 24.1 & 6.0 & 4.0 & 3.5 & 4.4 \\
\hline Never married & 11.6 & 15.9 & 95.4 & 96.4 & 4.2 & 9.6 & 2.0 & 3.7 & 2.5 & 1.5 \\
\hline \multicolumn{11}{|l|}{ Education (\%) } \\
\hline$<$ High school & 35.3 & 16.7 & 17.3 & 9.5 & 45.2 & 24.5 & 33.5 & 15.8 & 15.6 & 15.6 \\
\hline High school, trade cert., apprenticeship & 36.7 & 38.5 & 36.5 & 42.3 & 33.2 & 37.0 & 38.3 & 38.4 & 46.0 & 46.8 \\
\hline Tech. or teach. coll. & 14.5 & 13.4 & 18.7 & 12.7 & 11.4 & 11.4 & 15.4 & 13.9 & 14.0 & 11.5 \\
\hline$\geq$ University degree & 13.5 & 31.4 & 27.5 & 35.5 & 10.2 & 27.0 & 12.9 & 31.9 & 24.4 & 26.1 \\
\hline \multicolumn{11}{|l|}{ Religious affiliation (\%) } \\
\hline Protestant & 62.2 & 56.6 & 48.3 & 42.5 & 64.7 & 58.6 & 63.3 & 58.4 & 52.1 & 45.2 \\
\hline Roman Catholic & 21.7 & 19.9 & 25.7 & 26.6 & 20.1 & 18.2 & 21.8 & 19.3 & 20.3 & 19.6 \\
\hline Other $^{d}$ & 3.7 & 3.9 & 4.6 & 7.2 & 4.4 & 3.8 & 3.3 & 3.4 & 5.3 & 5.3 \\
\hline None & 12.3 & 19.6 & 21.4 & 23.7 & 10.8 & 19.4 & 11.6 & 18.8 & 22.3 & 30.0 \\
\hline \multicolumn{11}{|l|}{ Alcohol history (\%) } \\
\hline TW self report AD & 4.5 & 17.9 & 8.4 & 25.5 & 4.5 & 18.9 & 3.9 & 16.3 & - & - \\
\hline TW report of SP probs & 12.6 & 2.9 & - & - & 17.1 & 4.9 & 10.4 & 2.3 & - & - \\
\hline SP self report $A D$ & - & - & - & - & - & - & - & - & 8.1 & 23.2 \\
\hline
\end{tabular}

anterviews conducted 1992-1993.

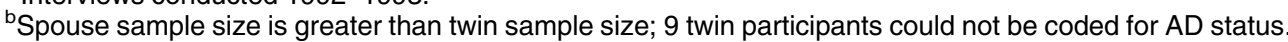

Interviews conducted 1994-1997.

dIncludes Jewish, Greek/Russian Orthodox, and Other categories.

TW, twin, SP, spouse.

included only for heterosexual relationships. Table 1 shows the number of respondents who had twin self-report, twin report on spouse, and spouse self-report data as well as a comparison of select sociodemographic variables for twin and spouse response groups. Respondents were included in the present analyses if any AD data were available (either twin, either twin's report on his/her spouse, or either twin's spouse).

\section{Measures}

The SSAGA, a structured diagnostic interview designed for genetic studies of alcoholism (Bucholz et al., 1994), was adapted for telephone administration and was used for both the twin and spouse interviews. Diagnostic assessments included lifetime history of DSM-IV AD (without the clustering criterion; the twin interview predated DSM-IV criteria) and other major psychiatric disorders, as well as family history reports for the respondent's spouse, parents, and cotwin (spouses were asked about their own parents and the twin to whom they were married, but were not asked about the cotwin's history). Telephone interviews were conducted by lay interviewers who received 2 weeks of training as well as continued in-service training. For quality control, interviews were audiotaped unless the respondent refused permission. Members of a twin pair were interviewed by different people so that the interviewers had no prior knowledge of any family history.

For the present analyses, the primary measure of interest was lifetime AD. From the twin and spouse self-report data, a DSM-IV AD diagnosis (without the clustering criterion) was created. Respondents were classified as AD if they had 3 or more AD symptoms lifetime. An additional report of spouse alcohol problems, based on the twin's report of his/her spouse's history (obtained during the twin interview), was also used. This measure was based on the twin's response to a single question: "Has drinking ever caused your spouse/partner to have problems with health, family, job or police, or other problems?". We combine twin reports of spousal alcohol problems and spousal self-report data in the same analysis to reduce the bias associated with the disproportionate nonresponse of spouses with AD (Little and Rubin, 1987). Spouse report of twin alcohol problems was not included in the present analyses.

\section{Analyses}

To include all available information, raw data were used for all analyses. Preliminary analyses examined the demographic characteristics of the sample, the prevalence of $\mathrm{AD}$, and the magnitude of the spousal correlation for AD. Prevalences were calculated using SAS software, version 9 (SAS Institute, 2000), and tetrachoric correlations were computed using PRELIS, as available within the statistical package LISREL (Jöreskog and Sörbom, 1996).

To assess whether spouse nonparticipation in the telephone interview phase was associated with alcohol problems, twin self-reported AD status, twin's report of his/her spouse's history of alcohol problems, and the interaction between sex and spouse's history of alcohol problems were entered into a logistic regression analysis predicting spouse nonparticipation in the interview assessment. Logistic regression analyses were conducted using the statistical package Stata, and included the Huber-White adjustment for the nonindependence of twin pairs (StataCorp., 2003).

To test whether the spousal correlation varied according to marital cohort/duration of marriage, respondents were divided into 6 roughly equal-sized marital cohort groups based on year of marriage: 1990 or later (10\% of twins and spouses), 1985 to 1989 (16\% of twins and spouses), 1980 to 1984 (17\% of twins and $18 \%$ of spouses, respectively), 1975 to 1979 (14, 15\%), 1970 to 1974 
(14, 15\%), and 1969 or earlier (29 and $26 \%$, respectively). This 6-level variable was converted into 5 dummy variables, with those married 1969 or earlier as the comparison group. These variables, along with husband's AD and the interaction between each cohort and husband's AD status, were entered into a logistic regression predicting the wife's AD. Logistic regression analyses were conducted using the statistical package Stata, and included the Huber-White adjustment for the nonindependence of twin-pairs (StataCorp., 2003). Two sets of logistic regressions were conducted in this manner: wife's self-report predicted from husband's self-report $(n=3,724)$, and wife's history (as reported by a male twin) predicted from husband's self-report $(n=1,674)$. A third series was run predicting the husband's history (as reported by a female twin) predicted from wife's self-report, using the appropriate interaction terms between the wife's AD status and the marital cohort $(n=2,987)$.

Twin pair correlations were calculated separately for identical [monozygotic (MZ)] and fraternal [dizygotic (DZ)] twins to gain preliminary insight into the most likely quantitative genetic model. Quantitative genetic theory has been described in detail elsewhere (Bulmer, 1980; Falconer, 1960; Keller and Coventry, 2005; Neale and Cardon, 1992; Plomin, 1990). In brief, genetic and environmental influences on variability for a given behavior can be estimated by comparing the pattern of correlations (or covariances) for groups that differ in their degree of genetic or environmental relatedness. The most common strategy is to compare MZ twins with DZ twins, because MZ twins share $100 \%$ of their genes, and DZ twins share $50 \%$ of their segregating genes on average. Quantitative genetic theory posits 4 main categories of influence on variance: additive genetic (A), nonadditive genetic ( $\mathrm{D}$; the 2 primary forms are dominance and epistasis, which are confounded in twin data; dominance is an interaction between the 2 alleles at 1 locus; epistasis is an interaction between multiple loci; see Falconer, 1960; Keller and Coventry, 2005; Neale and Cardon, 1992), shared environmental $(C$; environmental influences that make family members similar to each other; assumed shared to the same extent for MZ and DZ twins, as discussed below), and nonshared environmental (E; environmental influences that contribute to differences between family members; this component also includes error variance). Basic twin studies cannot estimate both D and C (the model would be underidentified; see, e.g., Sham, 1998), thus 1 of these components is selected for inclusion based on the twin correlations. The classic twin study is also limited in that the genetic consequences of assortative mating effects and some forms of gene-environmental correlation effects are confounded with true-shared environmental influences (see, e.g., Bulmer, 1980; Eaves et al., 1978; Keller and Coventry, 2005). An advantage of the twin-spouse design (as well as other extended twin-family designs) is the ability to tease apart AM, gene-environment correlation, and true $\mathrm{C}$ effects. The validity of the twin comparison is dependent on several assumptions, of which the equal environments assumption (i.e., that the environments in which MZ and DZ pairs are reared are equally similar) has raised the most concern. The concern is that $M Z$ twins might be raised in an environment that is more similar than that of DZ twins. If so, the MZ correlation could be greater than the DZ correlation because of increased environmental similarity, which would violate the principle that any greater MZ similarity stems exclusively from their genetic similarity, and would result in the overestimation of genetic influences on variability. Although this assumption has garnered much attention, research has generally found that violations of the equal environments assumption have little to no effect on most behaviors (Hettema et al., 1995; Kendler and Gardner, 1998; Kendler et al., 1993, 1994b; Xian et al., 2000). Although the twin-pair correlations provide insight into the magnitude of genetic and environmental contributions to variance in risk for $\mathrm{AD}$, quantitative genetic modeling is necessary to determine the statistical significance of the components.
All quantitative genetic analyses were conducted using the statistical package Mx (Neale et al., 2003). The primary model tested in these analyses is presented in Fig. 1; to depict paths that were allowed to differ across gender, Fig. 1 is written for an unlike-sex twin pair. For female-female twin pairs, the gender-specific paths would be comparable to the left side of the diagram for both twins; for malemale twin pairs, the gender-specific paths would be comparable to the right side of the diagram for both twins. The model includes 4 key components, signified by side brackets. Part "a" shows the classic quantitative genetic model, assumed standardized to unit phenotypic variance, in which twin data are used to assess the relative contributions of genetic and environmental factors to variation in risk for AD. For these analyses, a model with additive genetic (A), nonadditive genetic (D), and nonshared environmental (E) influences was selected based on the tetrachoric correlations. Part "b" assesses the extent of assortative mating for AD through the regression parameter $\mu$, which models the structural regression of partner phenotype on twin phenotype (without implication of unidirectional selection). The strength of $\mu$ reflects the degree of AM, with a positive value indicating that "like marries like" and a negative value indicating that "opposites attract." A number of alternative formulations of phenotypic assortative mating (e.g., Carey, 1986; Cloninger, 1980; Maes et al., 1998; Neale and McArdle, 1990; van Eerdewegh, 1982) lead to expectancies for the covariances of twin pairs and their spouses that are identical to those which may be derived from Fig. 1. Our analyses assumed that AM was equivalent across generations (i.e., that $\mathrm{AM}$ is in equilibrium). AM was constrained to be equal for men and women; this is necessarily the case unless AM is modeled as a multivariate process (Eaves and Heath, 1981). Part "c" of the model incorporates a spousal interaction effect in which spouses influence each other at the phenotypic level through the $\beta$ parameters. As it is plausible that 1 sex is more influenced by a spouse's behavior than is the other, we allowed for 2 types of spousal interaction in the initial model: $\beta_{1}$ indicates the extent to which a woman's behavior influences her husband's behavior, and $\beta_{2}$ indicates the extent to which a man's behavior impacts his wife's behavior. It is possible to estimate and differentiate between AM and SI in these analyses because we have data from twins and their spouses (Heath, 1987; Heath et al., 1985; Maes et al., 1998; Sakai et al., 2004; Truett et al., 1994). The presence of twin and spouse data increases the number of available statistics to 7 (i.e., correlations/covariances between: husband-wife, MZ and DZ twin-cotwin, MZ and DZ twin-cotwin's spouse, and MZ and DZ spouse-spouse), with only 4 unknowns being estimated (i.e., AM, SI, additive genetic influences, and nonadditive genetic influences; because $\mathrm{A}+\mathrm{D}+\mathrm{E}=1, \mathrm{E}$ is constrained once $\mathrm{A}$ and $\mathrm{D}$ are estimated). As discussed by Madden et al. (2002), assortment would yield comparatively larger correlations between twin and cotwin's spouse and between the spouses of twin pairs than would spousal interaction effects (assuming the spousal associations are positive).

At the bottom of the Fig. 1d, the measurement model connecting the latent constructs and the observed constructs is depicted (Loehlin, 1992). Because we have both spouse self-report data and twin ratings of spouse history, we are able to model separate regressions for twin rating of his/her spouse on spouse self-report ( $L_{21}$ for male spouses and $L_{22}$ for female spouses) and on twin self-report ( $L_{11}$ for female twins and $L_{12}$ for male twins), with the latter parameter a measure of "rater bias", i.e., the tendency for ratings of alcohol problems to be influenced by the individual's own history. Finally, although not shown on the diagram, we did allow for gender differences in total variance of AD. The variance of the women was constrained to be 1.0, and the variance of the men was modeled as a scalar multiple of the female variance. Thus, we required that the proportions of variance in risk for $\mathrm{AD}$ attributable to genetic and environmental factors be equal for men and women, an assumption justified by earlier analyses with these data (Heath et al., 1997a).

Because we used raw data, each model provided twice the negative $\log$ likelihood as an index of fit. This index is not interpretable 


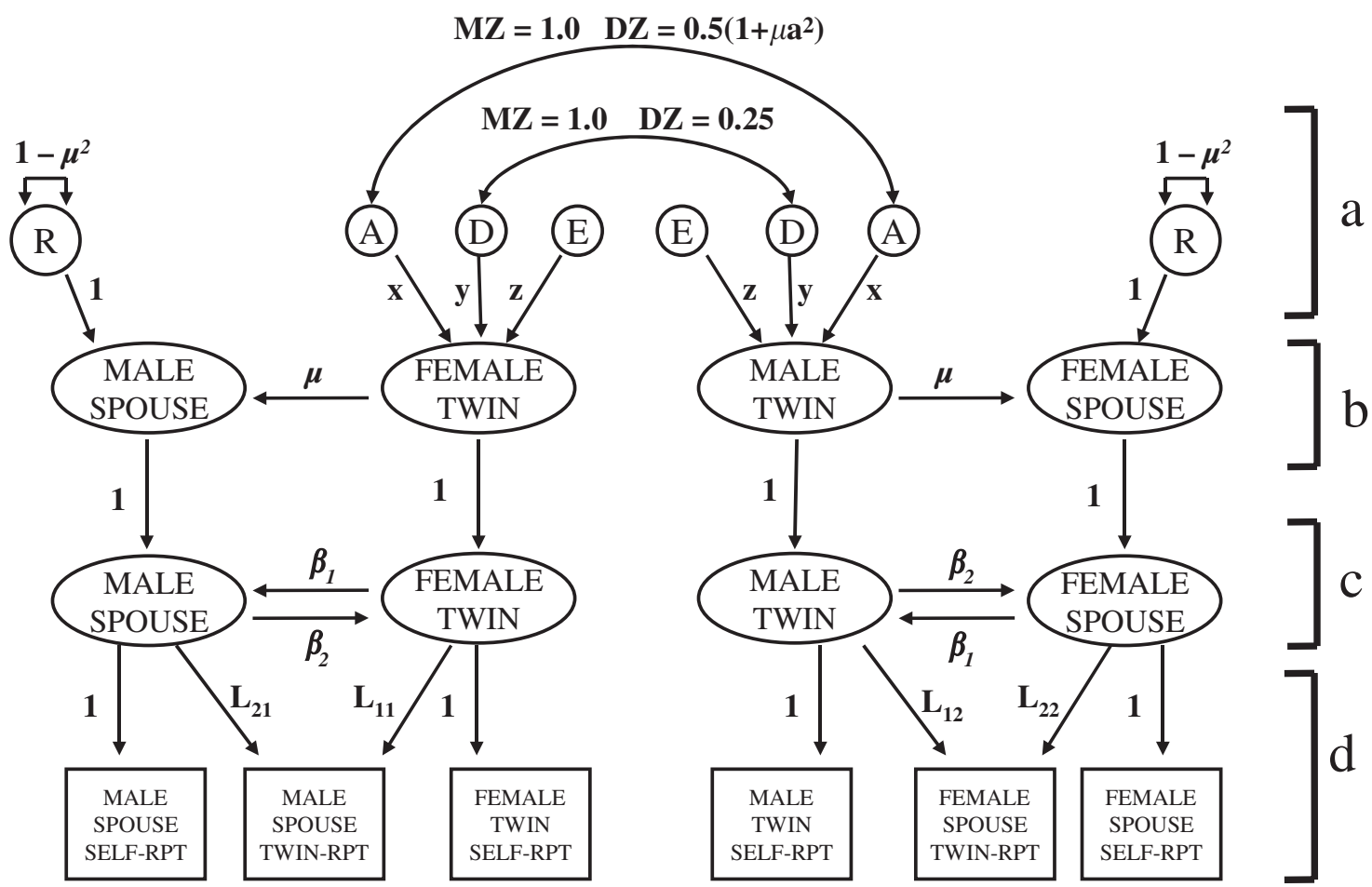

Fig. 1. Initial quantitative genetic model assessing the influences of genetic and environmental factors, assortative mating, and spousal interactions on variability in risk for alcohol dependence. Notes: to depict gender-specific paths, this diagram shows the paths for an unlike-sex twin pair, with the left side representing a female twin and male spouse, and the right side representing a male twin and female spouse. a, Standard quantitative genetic model; $b$, assortative mating component; $c$, spousal interaction component; $d$, measurement model. A, additive genetic influences, $D$, nonadditive genetic influences, $\mathrm{E}$, nonshared environmental influences, $\mathrm{R}$, residual variance of the spouse after adjustment for assortative mating, standardized to 1.0 for our analyses, $\mu$, assortative mating effect, $\beta$, reciprocal spousal interaction effect, $L_{11}$ and $L_{12}$, rater bias effects (impact of respondent status on respondent's report of spouse status), $L_{21}$ and $L_{22}$, regression of twin report on spouse's actual phenotype (index of the degree to which 1 individual can accurately report on his/her spouse); $\mu$ increases the additive genetic correlation between DZs from 0.5 to $0.5\left(1+\mu a^{2}\right)$ where $a^{2}$ is the heritability.

by itself, but when the solution from 1 model is subtracted from the solution of a nested submodel (i.e., 1 with fewer parameters), the difference in these solutions can be interpreted as a chi-square with the degrees of freedom equal to the difference in the number of parameters estimated. This process of testing submodels and obtaining the change in fit is an appropriate method for determining the optimal solution; the results so obtained are usually (but not always) the same as those obtained by calculating the confidence intervals for specified parameters (Eaves et al., 1978).

\section{RESULTS}

\section{Preliminary Analyses}

Lifetime Prevalence of Alcohol Dependence. The rate of DSM-IV AD was $4.5 \%$ for the female twins and $17.9 \%$ for the male twins. Many of these twins also indicated whether their spouse had a history of alcohol problems, with $12.6 \%$ of the women reporting their husbands did and 2.9\% of the men indicating their wives did. Of the spouses interviewed, $23.2 \%$ of the husbands of female twins and $8.1 \%$ of the wives of male twins met DSM-IV AD criteria. The prevalence of alcohol problems was lower based on twin report of spouse than on spouse's own self-report. This is likely because we used a single item for the twin report on spouse, whereas the spouse self-report measure assessed DSM-IV AD.
Spouse Nonparticipation. Logistic regression analyses indicated that spouses who were reported to have a history of alcohol problems (by twin report) were less likely to complete a telephone interview $(\mathrm{OR}=1.80$, $\mathrm{CI}=1.46-2.21)$. Neither the twin's own AD nor the interaction term was significant.

Spousal Correlations. All raw correlations between husbands and wives were indicative of spousal association. The correlation between husbands and wives based on the self-report of each was 0.25 ; the correlation between wife self-report and her report of husband history was 0.38; the correlation between husband self-report and his report of wife history was 0.34 . The slightly higher correlations when 1 person provided both self and spouse histories suggests the presence of some rater bias. The third series of spousal correlations provides modest support for the validity of the twin's report on spouse history: the correlation between wife's self report and wife's history (based on male twin's report) was 0.50 , and the correlation between husband's self report and husband's history (based on female twin's report) was 0.45 .

Impact of Marital Duration. In no case was the interaction between the husband's AD status and marital cohort significant ( $p$-value range: $0.19-0.94$ ), and in only 1 case was the interaction between the wife's AD status 
Table 2. Full and Reduced Quantitative Genetic Models Assessing the Influences of Genetic and Environmental Factors, Assortative Mating, and Spousal Interactions on Variability in Risk for Alcohol Dependence

\begin{tabular}{|c|c|c|c|c|c|}
\hline Model & & $\begin{array}{l}\text { Compared } \\
\text { to model: }\end{array}$ & $\Delta \chi^{2}$ & $\Delta \mathrm{df}$ & Significance \\
\hline 1. & $\begin{array}{l}\text { Full model: A; D; E; assortative mating; spousal interaction; } \\
\text { gender differences in rater bias, regression of report on spouse phenotype, } \\
\text { spousal interaction; total variance }\end{array}$ & - & - & - & - \\
\hline 2. & Drop female rater bias $\left(L_{11}=0\right)$ & 1 & 30.044 & 1 & $p<0.0001$ \\
\hline 3. & Drop male rater bias $\left(L_{12}=0\right)$ & 1 & 5.373 & 1 & $p=0.02$ \\
\hline 4. & Drop regression of female report on spouse phenotype $\left(L_{21}=0\right)$ & 1 & 61.347 & 1 & $p<0.0001$ \\
\hline 5. & Drop regression of male report on spouse phenotype $\left(L_{22}=0\right)$ & 1 & 16.336 & 1 & $p<0.0001$ \\
\hline 6. & Drop non-additive genetic influences $(D=0)$ & 1 & 0.888 & 1 & $p=0.35$ \\
\hline 7. & Drop all genetic influences $(\mathrm{A}$ and $D=0)$ & 6 & 64.883 & 1 & $p<0.0001$ \\
\hline 8. & $\begin{array}{l}\text { No gender differences }{ }^{\mathrm{a}}\left(L_{11}=L_{12}, L_{21}=L_{22}, \beta_{1}=\beta_{2} \text {, }\right. \\
\text { male variance }=\text { female variance })\end{array}$ & 6 & 2.650 & 4 & $p=0.62$ \\
\hline 9. & Drop assortative mating $(\mu=0)$ & 8 & 3.064 & 1 & $p=0.08$ \\
\hline 10. & Drop reciprocal spousal interaction $(\beta=0)$ & 8 & 0.350 & 1 & $p=0.55$ \\
\hline 11. & Drop all spousal association ( $\mu$ and $\beta=0)$ & 8 & 46.939 & 2 & $p<0.0001$ \\
\hline
\end{tabular}

${ }^{\text {a } F i n a l ~ m o d e l, ~ i n c l u d e s ~} \mathrm{~A}, \mathrm{E}, \mu, \beta, L_{11}=L_{12}, L_{21}=L_{22}, \beta_{1}=\beta_{2}$, male variance $=$ female variance.

$A$, additive genetic influences, $D$, non-additive genetic influences.

and marital cohort significant ( $p$-value range: $0.03-0.46$ ). These data are available from the first author upon request. Because there was no evidence of a marital cohort/duration effect, we did not control for marital cohort in the quantitative genetic analyses.

Twin Pair Correlations. The correlations were 0.56 for MZF, 0.50 for MZM, 0.28 for DZF, 0.10 for DZM, and 0.26 for unlike-sex DZ (DZFM) twin pairs. The correlation for the MZF pairs is twice the size of the correlation for DZF pairs, suggesting a model with additive genetic and nonshared environmental influences on variability. The MZM correlation is more than twice the DZM correlation, suggesting that there may be dominant genetic influences as well as additive genetic and nonshared environmental influences on variability in risk for AD. That the DZFM correlation is not less than the samesex DZ correlations suggests that there are not strong sex-specific genetic effects. Tetrachoric correlations calculated for a model without gender-specific influences indicated an $\mathrm{MZ}$ correlation of 0.58 and a DZ correlation of 0.21 , suggestive of a model with additive genetic, nonadditive genetic, and nonshared environmental influences on variability in risk for $\mathrm{AD}$.

\section{Quantitative Genetic Model Fitting}

Because a previous analysis with these data suggested that there are not sex-specific genetic effects for AD in this sample (Heath et al., 1997a), and as the DZFM correlations were not smaller than the same-sex DZ correlations, we used the ADE model suggested by the overall MZ and DZ tetrachoric correlations and equated the proportions of variance attributable to each component across men and women in our initial quantitative genetic model. The results of the model-fitting analyses are presented in
Table 2 (model fit and statistical significance) and Table 3 (parameter estimates and confidence intervals). Model 1, the full model (depicted in Fig. 1, with parameter estimates in Table 3), suggested that slightly more than half of the variance in risk for AD is attributable to genetic factors $\left(a^{2}=0.30\right.$ and $\left.d^{2}=0.24\right)$, with nonshared environmental influences also explaining a substantial proportion of the variance in risk for $\operatorname{AD}\left(e^{2}=0.46\right)$. There was also evidence of modest positive AM for AD $(\mu=0.30)$, suggesting that individuals who are at risk of becoming alcohol dependent are more likely to marry individuals who are also at risk. The reciprocal SI suggested that there might be gender differences in how an individual's behavior is impacted by his/her spouse's behavior. The SI coefficient was 0.14 from females to males, suggesting that a man with an AD wife is at increased risk of being alcohol dependent. In contrast, the SI coefficient was -0.17 from males to females, suggesting that a woman with an AD husband is at reduced risk of being AD. For both men and women, there was modest evidence that an individual's own AD impacted his/her report of his/her spouse ( $L_{11}=0.30$ for female twins reporting about their male spouse; $L_{12}=0.20$ for male twins reporting about their female spouse). These estimates suggest that alcoholdependent individuals are more likely to report that their spouse has a history of alcohol problems (this effect is independent of and should not be confused with the actual increased rate of $\mathrm{AD}$ in spouses of $\mathrm{AD}$ individuals). There was also evidence that the twin's report of his/her spouse was associated with the spouse's actual phenotype ( $L_{21}=0.39$ for women reporting about their husbands, and $L_{22}=0.44$ for men reporting on their wives). Finally, the full model suggested that the total variance in risk for AD was somewhat smaller for men than for women: with the female variance set to 1.00 , the total male variance was 0.91 . 
Table 3. Parameter Estimates and 95\% Confidence Intervals for the Full and Final Models ${ }^{a}$

\begin{tabular}{|c|c|c|c|}
\hline \multirow[b]{2}{*}{ Parameter } & \multicolumn{2}{|c|}{ Full model } & \multirow[b]{2}{*}{ Final model } \\
\hline & $\begin{array}{l}\text { Female twins with a } \\
\text { male spouse }\end{array}$ & $\begin{array}{l}\text { Male twins with a } \\
\text { female spouse }\end{array}$ & \\
\hline Additive genetic $(\mathrm{A})$ & $0.30(0.00-0.91)$ & $=$ Females & $0.49(0.37-0.58)$ \\
\hline Nonadditive genetic (D) & $0.24(0.00-0.66)$ & $=$ Females & - \\
\hline Nonshared environment (E) & $0.46(0.31-0.59)$ & $=$ Females & $0.51(0.41-0.59)$ \\
\hline Assortative mating $(\mathrm{AM} ; \mu)$ & $0.30(0.28-0.88)$ & $=$ Females & $0.45(0.38-0.78)$ \\
\hline Spousal interaction $\left(\mathrm{SI} ; \beta_{1}, \beta_{2}\right)$ & $0.14(0.01-0.56)$ & $-0.17(-0.50-0.11)$ & $-0.10(-0.24--0.10)$ \\
\hline Rater bias $\left(L_{11}, L_{12}\right)$ & $0.30(0.20-0.40)$ & $0.20(0.05-0.27)$ & $0.27(0.19-0.29)$ \\
\hline Regression of respondent's report on spouse $\left(L_{21}, L_{22}\right)$ & $0.39(0.30-0.47)$ & $0.44(0.24-0.62)$ & $0.40(0.31-0.40)$ \\
\hline \multicolumn{4}{|l|}{ Spousal correlation (est.) } \\
\hline TW and SP self-report & 0.29 & 0.29 & 0.29 \\
\hline TW report on self and SP & 0.41 & 0.32 & 0.39 \\
\hline
\end{tabular}

a Labels in parentheses match the labels in Fig. 1; in the Final Model (Model 8 in Table 2), there is only one $\beta, L_{11}=L_{12}$, and $L_{21}=L_{22}$. A, D, and E are proportions of variance. TW, twin; SP, spouse.

\section{Measurement Model Assessment}

In models 2 to 5 , we tested the measurement model (i.e., whether the latent structures were significantly associated with the observed phenotypes). Models 2 and 3 show that for women and men, respectively, the rater biases were significant. Models 4 and 5 show that for women and men, respectively, the twin's report of his/her spouse was significantly associated with the spouse's actual phenotype. Thus, all 4 of these paths were retained in later analyses.

Genetic Influences on Variability in Risk for AD. In model 6, we tested whether the nonadditive genetic influences on variability in risk for AD were statistically significant. The nonadditive path could be eliminated from the model without a significant decrease in fit, implying that the effects of dominant genetic factors were not significant. However, power to detect nonadditive genetic effects in twin data is known to be limited and as such we cannot exclude the possibility of nonadditive genetic influences contributing to genetic variance (see, e.g., Martin et al., 1978). This model yielded a heritability estimate of 0.53 , with nonshared environmental influences accounting for the remaining variance in risk for $\mathrm{AD}$. We tested an additional model without any genetic influences on variability in risk for AD (model 7), and this resulted in a substantial decrement in model fit. Thus, there are significant genetic influences on variability in risk for $\mathrm{AD}$, and the most parsimonious model is 1 with additive genetic effects as well as nonshared environmental influences. Model 6 became the base model for the next series of submodels.

Gender Differences. In model 8, we assessed simultaneously whether there were gender differences for SI (i.e., does $\beta_{1}=\beta_{2}$ ), rater bias (i.e., does $L_{11}=L_{12}$ ), and the association between twin report of spouse and the spouse's self-reported status (i.e., does $L_{21}=L_{22}$ ). This model yielded a reciprocal SI $(\beta)$ of -0.10 , a rater bias of 0.27 , and an association between twin report of spouse and spouse self-report of 0.40 . Because no parameters were estimated separately for men and women, this model by default also resulted in equal variances for the men and women. The AM parameter was $\mu=0.45$, again suggesting that "like marries like." The increase in the AM parameter, relative to that observed in the full model, is a function of the negative value for SI (for both women and men). The spousal correlation was 0.29 . The decrement in model fit was not significant $\left(\chi_{4}^{2}=2.65\right)$, indicating that there were no gender differences on these parameters in this sample. Thus, model 8 became the base model for the final series of analyses.

Assortative Mating and Reciprocal Spousal Interaction Effects. The final series of models assessed the significance of the AM and reciprocal SI effects. When a model with SI but no AM was tested (model 9), the reciprocal SI became positive $(\beta=0.15)$, and the change in model fit was not significant. When a model with AM but no SI was tested (model 10), the AM parameter decreased somewhat $(\mu=0.29)$, and the change in model fit was not significant. Because either parameter could be removed without a significant decrement in model fit, we tested a final model in which both AM and SI were removed (model 11), and the decrement in fit was significant and substantial $\left(\chi_{2}^{2}=46.94\right)$. This suggests that there are spousal influences associated with $\mathrm{AD}$, but that we lack the power to differentiate between AM and SI processes with the present data. Given the significant reduction in model fit when AM and SI were dropped simultaneously, we selected model 8 as the best-fitting model. We present the final model parameter estimates and confidence intervals in Table 3.

\section{DISCUSSION}

The present analysis expands the body of literature on spousal associations for alcohol dependence by simultaneously assessing both assortative mating and spousal interaction, processes which can be disentangled by using 
a genetically informative twin-family design (see Heath, 1987; Heath and Eaves, 1985; Maes et al., 1998; Neale and Cardon, 1992; Sakai et al., 2004; Truett et al., 1994; Vanyukov et al., 1996). An additional contribution of the present analysis is the direct assessment of gender differences in spousal interaction effects. Furthermore, because we had twin self-report data as well as (in many cases) spouse data from both spouse self-report and twin report, we were able to assess: (1) the extent to which an individual's AD status impacts his/her reporting of others' problems, and (2) the degree of association between 2 people's reports of an individual's AD history (the spouse self-report and the twin's report of his/her spouse).

The present analyses provide evidence of significant spousal associations for AD, with our estimated spousal correlation of 0.29 (in the final model) being remarkably similar to the estimate of 0.27 obtained by Kendler et al. (1994a) for their "broad" definition of alcoholism, to the estimate of 0.31 obtained by Stallings et al. (1997), and to the estimate of 0.28 obtained by Sakai et al. (2004) for their "control" sample (community residents, including those with a psychiatric or AD history). Our estimate is somewhat larger than those obtained by Maes et al. (1998) (0.12 and 0.07 for 2 separate population-based samples) and by Agrawal et al. (2006) (0.15), and somewhat smaller than the correlation obtained by Sakai et al. (2004) with their "patient" sample (0.40; patients in a substance abuse treatment facility).

To our knowledge, these analyses represent the first attempt to model simultaneously (and thereby disentangle) multiple sources of spousal resemblance for $\mathrm{AD}$ a sample of both male and female twins (Agrawal et al., 2006, analyzed only female twins and their male spouses). We were able to drop either AM or SI individually but not both simultaneously, suggesting that although there was significant spousal similarity, power was insufficient to differentiate between the 2 potential sources of similarity. Although it did not reach official statistical significance, the change in model fit when the AM parameter was deleted was suggestive $\left(\chi_{1}^{2}=3.06, p=0.08\right)$. Our findings regarding the relative contributions of AM and SI are consistent with previous studies (Agrawal et al., 2006; Maes et al., 1998). Maes et al. (1998) (without a genetically sensitive design) attempted to examine the evidence for each process by comparing the age of marriage to psychiatric disorder onset, with the expectation that if the onset of the disorder preceded the marriage, then marital interaction could not explain spousal similarity for psychiatric disorders (including AD). Their analysis suggested that assortment was probably primary for a young sample, but that marital interactions could at least partly explain similarity in a sample roughly 20 years older. Analyzing the same female twins we studied here, and excluding the male twins, Agrawal et al. (2006), found significant AM, but no reciprocal SI once AM was included. In terms of model specification, our model 10 (AM only; AM path $=0.29$ ) is the 1 most comparable to the final model specified by Kendler et al. $(1994 \mathrm{a} ;$ AM path $=0.22)$ and Agrawal et al. (2006; AM path $=0.16)$. The estimate of AM in our final model $(0.45$, model 8$)$ is somewhat larger than that of other researchers because ours included the negative effect for SI as well as the positive effect for AM. The difference between the estimate of 0.29 (AM only) and 0.45 (AM and SI) underscores the importance of allowing for both processes.

Although the AM parameter was positive in all of our analyses (indicating that an individual who is at increased risk of developing AD is at increased risk of marrying someone with a similar predisposition), the direction of the SI parameter differed depending on whether AM was modeled at the same time. In models that included SI only, the SI effect was positive, suggesting that having a spouse who is alcohol dependent increases an individual's likelihood of problem drinking. However, in models that also included AM, SI was negative, suggesting that once the AM effects have been accounted for, any additional SI effects are protective. Although the negative SI effect was not anticipated, 1 possible explanation for this finding is that once an individual has a spouse with $\mathrm{AD}$, the nonproblem-drinker reduces consumption in reaction to the other's excess. This combination of positive AM and negative SIs also highlights the potential for misinterpretation that can occur when only 1 process is studied, as has been the case in much of the literature to date.

Another contribution of the present analyses is the examination of potential gender differences in several aspects of the spousal association. Because Agrawal et al. (2006) and Kendler et al. (1994a) both analyzed only female twins and their spouses, neither of the previous studies was able to address this issue. It would not have been surprising to have found gender differences in the magnitude and/or direction of SI, in rater bias, or in the extent of association between an individual's report of spouse alcohol problems and the spouse's own self report. That these parameters could be equated for men and women suggests that the differences are not substantial; further research with other samples will provide additional insight into this finding.

Another important contribution of the present analyses is the direct assessment of rater bias, for which our data suggest a modest effect of 0.27 (accounting for only about $7 \%$ of the variance in the rater's report). As was found by Heath et al. (1985) for reports of education level, the positive rater bias indicates that people see others (their spouse, in this case) as being similar to them.

Finally, because for many spouses we had both the spouse self-report of their AD and the twin's report of the spouse's alcohol problems, we were also able to directly assess the extent to which an individual's report of his/her spouse's history of alcohol problems is associated with the spouse's own report of AD. Although the parameter 
estimate of 0.40 was modest, it was significant, indicating that men and women can shed some light on their spouse's self-perceived behavioral history. Thus, family history data are of use when direct assessments are not available or feasible. The modest size of this coefficient may be partially attributable to the difference in the measures; the twin report of spouse problems was based on a single item from DSM-IV criteria (family/work/legal problems), whereas the spouse self-report was based on full diagnostic criteria. Rater bias effects are also likely to reduce the association between multiple reporters.

There are some limitations that warrant discussion. First, these data were collected from a volunteer panel of Australian twins. Thus, certain subpopulations may be systematically under- or overrepresented (e.g., although the sample covers a broad range of educational and socioeconomic backgrounds, well-educated individuals are somewhat overrepresented; see Heath et al., 1997a). As with most volunteer panels, the study has somewhat more women and $\mathrm{MZ}$ twins relative to population rates. In addition, given that our respondents are virtually all of European ancestry (as was the nonAboriginal population of Australia for this cohort; the Aboriginal population was not represented in the Twin panel), the present results might not generalize to other ethnic groups. It is also quite likely that power limitations played a role in some of our analyses. Although the base sample of 5,974 twins (including 2,702 complete pairs) is sufficient for the basic quantitative genetic analysis of $\mathrm{AD}$, the power for assessing spousal associations is somewhat lower because not all twins were married, not all of the married twins had a spouse complete an interview, and not all pairs were concordant for having spouse data (this last factor reduces the precision of the estimated correlation between 1 twin and his/her cotwin's spouse). The potential for low power was manifested by our ability to remove either AM or SI from the model without a decrement in fit, but our inability to delete the 2 effects simultaneously.

In summary, the analyses presented here provide further corroboration of nonrandom mating for AD risk, and extend the field by suggesting that both AM and SI may be important contributors to the association. Additional work with larger samples may help further differentiate between assortative mating effects and spousal interactions (especially the potential protective effect of SI after $\mathrm{AM}$ has been included in the model), and may shed light on the presence/absence of gender differences in the nature and extent of spousal influence. Future work examining potential cross-assortment for AD risk and other psychiatric disorders, and the ordering of disorder onsets is also warranted.

\section{REFERENCES}

Agrawal A, Heath AC, Grant JD, Pergadia ML, Statham DJ, Bucholz KK, Martin NG, Madden PAF (2006) Assortative mating for cigarette smoking and for alcohol consumption in female Australian twins and their spouses. Behav Genet 36:553-566.

Bucholz KK, Cadoret R, Cloninger CR, Dinwiddie SH, Hesselbrock VM, Nurnberger JI Jr, Reich T, Schmidt I, Schuckit MA (1994) A new, semi-structured psychiatric interview for use in genetic linkage studies: a report on the reliability of the SSAGA. J Stud Alcohol 55:149-158.

Bulmer MG (1980) The Mathematical Theory of Quantitative Genetics. Clarendon Press, Oxford.

Caetano R, Cunradi C (2002) Alcohol dependence: a public health perspective. Addiction 97:633-645.

Carey G (1986) A general multivariate approach to linear modeling in human genetics. Am J Hum Genet 39:775-786.

Cloninger CR (1980) Interpretation of intrinsic and extrinsic structural relations by path analysis: theory and applications to assortative mating. Genet Res Camb 36:133-145.

Compton WM, Conway KP, Stinson FS, Colliver JD, Grant BF (2005) Prevalence, correlates, and comorbidity of DSM-IV antisocial personality syndromes and alcohol and specific drug use disorders in the United States: results from the National Epidemiologic Survey on Alcohol and Related Conditions. J Clin Psychiatry 66:677-685.

Cotton NS (1979) The familial incidence of alcoholism: a review. J Alcohol Stud 40:89-116.

Coventry WL, Keller MC (2005) Estimating the extent of parameter bias in the classical twin design: a comparison of parameter estimates from extended twin-family and classical twin designs. Twin Res Hum Genet 8:214-223.

Dawson DA, Grant BF (1998) Family history of alcoholism and gender: their combined effects on DSM-IV alcohol dependence and major depression. J Stud Alcohol 59:97-106.

Eaves L (1979) The use of twins in the analysis of assortative mating. Heredity 43:399-409.

Eaves LJ, Fulker DW, Heath AC (1989) The effects of social homogamy and cultural inheritance on the covariances of twins and their parents: a LISREL model. Behav Genet 19:113-122.

Eaves LJ, Heath AC (1981) Sex-limitation and "asymmetric" assortative mating. Prog Clin Biol Res 69 (Part B): 73-86.

Eaves LJ, Heath AC, Martin NG (1984) A note on the generalized effects of assortative mating. Behav Genet 14:371-376.

Eaves LJ, Last KA, Young PA, Martin NG (1978) Model-fitting approaches to the analysis of human behaviour. Heredity 41:249-320.

Falconer DS (1960) Introduction to Quantitative Genetics. The Ronald Press Company, New York.

Fisher RA (1918) The correlation between relatives on the supposition of Mendelian inheritance. Trans R Soc Edinburgh 52:399-433.

Grant BF, Dawson DA, Stinson FS, Chou SP, Dufour MC, Pickering RP (2004a) The 12-month prevalence and trends in DSM-IV alcohol abuse and dependence: United States, 1991-1992 and 2001-2002. Drug Alcohol Depend 72:223-234.

Grant BF, Stinson FS, Dawson DA, Chou SP, Dufour MC, Compton W, Pickering RP, Kaplan K (2004b) Prevalence and co-occurrence of substance use disorders and independent mood and anxiety disorders: results from the National Epidemiologic Survey on Alcohol and Related Conditions. Arch Gen Psychiatry 61:807-816.

Hall RL, Hesselbrock VM, Stabenau JR (1983) Familial distribution of alcohol use: II. Assortative mating of alcoholic probands. Behav Genet 13:373-382.

Heath AC (1987) The analysis of marital interaction in cross-sectional twin data. Acta Genet Med Gemellol 36:41-49.

Heath AC, Berg K, Eaves LJ, Solaas MH, Sundet J, Nance WE, Corey LA, Magnus P (1985) No decline in assortative mating for educational level. Behav Genet 15:349-369.

Heath AC, Bucholz KK, Madden PAF, Dinwiddie SH, Slutske WS, Bierut LJ, Statham DJ, Dunne MP, Whitfield JB, Martin NG (1997a) Genetic and environmental contributions to alcohol dependence risk in a national twin sample: consistency of findings in men and women. Psychol Med 27:1381-1396. 
Heath AC, Cloninger CR, Martin NG (1994) Testing a model for the genetic structure of personality: a comparison of the personality systems of Cloninger and Eysenck. J Pers Soc Psychol 66:762775.

Heath AC, Eaves LJ (1985) Resolving the effects of phenotype and social background on mate selection. Behav Genet 15:15-30.

Heath AC, Eaves LJ, Nance WE, Corey LA (1987) Social inequality and assortative mating: cause or consequence? Behav Genet 17: 9-17.

Heath AC, Martin NG (1994) Genetic influences on alcohol consumption patterns and problem drinking: results from the Australian NH \& MRC twin panel follow-up survey. Ann NY Acad Sci 780: $72-85$.

Heath AC, Slutske WS, Madden PAF (1997b) Gender differences in the genetic contribution to alcohol consumption patterns, in Gender and Alcohol: Individual and Social Perspectives (Wilsnack RW, Wilsnack SC eds), pp. 114-149. Rutgers Center of Alcohol Studies, New Brunswick, NJ.

Hettema JM, Neale MC, Kendler KS (1995) Physical similarity and the equal-environment assumption in twin studies of psychiatric disorders. Behav Genet 25:327-335.

Hopfer CJ, Stallings MC, Hewitt JK, Crowley TJ (2003) Family transmission of marijuana use, abuse, and dependence. J Am Acad Child Adolesc Psychiatry 42:834-841.

Ioannidis JPA, Trikalinos TA, Khoury MJ (2006) Implications of small effects sizes of individual genetic variants on the design and interpretation of genetic association studies of complex diseases. Am J Epidemiol 164:609-614.

Jacob T, Waterman B, Heath A, True W, Bucholz KK, Haber R, Scherrer J, Fu Q (2003) Genetic and environmental effects on offspring alcoholism: new insights using an offspring-of-twins design. Arch Gen Psychiatry 60:1265-1272.

Jang KL, Livesley WJ, Vernon PA (1997) Gender-specific etiological differences in alcohol and drug problems: a behavioral genetic analysis. Addiction 92:1265-1276.

Jardine R, Martin NG (1984) Causes of variation in drinking habits in a large twin sample. Acta Genet Med Gemellogiae 33:435-450.

Jöreskog K, Sörbom D (1996) LISREL 8: User's Reference Guide. Scientific Software International Inc., Chicago, IL.

Keller MC, Coventry WL (2005) Quantifying and addressing parameter indeterminacy in the classical twin design. Twin Res Hum Genet 8:201-213

Kendler KS, Gardner CO (1998) Twin studies of adult psychiatric and substance dependence disorders: are they biased by differences in the environmental experiences of monozygotic and dizygotic twins in childhood and adolescence? Psychol Med 28:625-633.

Kendler KS, Heath AC, Neale MC, Kessler RC, Eaves LJ (1992) A population-based twin study of alcoholism in women. JAMA 268:1877-1882.

Kendler KS, Neale MC, Heath AC, Kessler RC, Eaves LJ (1994a) A twin-family study of alcoholism in women. Am J Psychiatry 151: 707-715.

Kendler KS, Neale MC, Kessler RC, Heath AC, Eaves LJ (1993) A test of the equal-environments assumption in twin studies of psychiatric illness. Behav Genet 23:21-27.

Kendler KS, Neale MC, Kessler RC, Heath AC, Eaves LJ (1994b) Parental treatment and the equal environment assumption in twin studies of psychiatric illness. Psychol Med 24:579-590.

Little RJA, Rubin DB (1987) Statistical Analysis with Missing Data. John Wiley \& Sons, New York.

Loehlin JC (1992) Latent Variable Models: An Introduction to Factor, Path, and Structural Analysis, 2nd ed. Lawrence Erlbaum Associates, Hillsdale, NJ

Madden PAF, Bucholz KK, Todorov AA, Grant JD, Heath AC (2002) The assessment of peer selection and peer environmental influences on behavior using pairs of siblings or twins. Twin Res 5: $38-43$.
Maes HHM, Neale MC, Kendler KS, Hewitt JK, Silberg JL, Foley DL, Meyer JM, Rutter M, Simonoff E, Pickles A, Eaves LJ (1998) Assortative mating for major psychiatric diagnoses in two population-based samples. Psychol Med 28:1389-1401.

Martin NG, Eaves LJ, Kearsey MJ, Davies P (1978) The power of the classical twin study. Heredity 40:97-116.

McGue M (1994) Genes, environment, and the etiology of alcoholism, in The Development of Alcohol Problems: Exploring the Biopsychosocial Matrix of Risk (Zucker R, Boyd G, Howard J eds), pp 1-40. National Institute on Alcohol Abuse and Alcoholism Research Monograph \# 26, Rockville, MD.

McGue M, Pickens RW, Svikis DS (1992) Sex and age effects on the inheritance of alcohol problems: a twin study. J Abnorm Psychol 101:3-17.

Merikangas KR (1990) The genetic epidemiology of alcoholism. Psychol Med 20:11-22.

Neale MC, Boker SM, Xie G, Maes HH (2003) Mx: Statistical Modeling, 6th ed. VCU Box 900126, Department of Psychiatry, Richmond, VA.

Neale MC, Cardon LR (1992) Methodology for Genetic Studies of Twins and Families. Kluwer Academic Publishers, Boston.

Neale MC, McArdle JJ (1990) The analysis of assortative mating: a LISREL model. Behav Genet 20:287-296.

Nurnberger JI, Wiegand R, Bucholz K, O'Connor S, Meyer ET, Reich T, Rice J, Schuckit M, Petti T, Bierut L, Hinrichs AL, Kuperman S, Hesselbrock V, Porjesz B (2004) A family study of alcohol dependence: coaggregation of multiple disorders in relatives of alcohol-dependent probands. Arch Gen Psychiatry 61:1246-1256.

Plomin R (1990) Nature and Nurture: An Introduction to Human Behavioral Genetics. Brooks/Cole, Pacific Grove, CA.

Prescott CA (2001) The genetic epidemiology of alcoholism: sex differences and future directions, in Alcohol in Health and Disease (Agarwal DP, Seitz HK eds), pp 125-149. Marcel Dekker Inc., New York.

Prescott CA (2002) Sex differences in the genetic risk for alcoholism. Alcohol Res Health 26:264-273.

Prescott CA, Aggen SH, Kendler KS (1999) Sex differences in the sources of genetic liability to alcohol abuse and dependence in a population-based sample of U.S. twins. Alcohol Clin Exp Res 23: $1136-1144$

Prescott CA, Kendler KS (2000) Influence of ascertainment strategy on finding sex differences in genetic estimates from twin studies on alcoholism. Am J Med Genet (Neuropsych Genet) 96:754-761.

Reynolds CA, Baker LA, Pedersen NL (1996) Models of spouse similarity: application to fluid ability measured in twins and their spouses. Behav Genet 26:73-88.

Sakai JT, Stallings MC, Mikulich-Gilbertson SK, Corley RP, Young SE, Hopfer CJ, Crowley TJ (2004) Mate similarity for substance dependence and antisocial personality disorder symptoms among parents of patients and controls. Drug Alcohol Depend 75:165-175.

SAS Institute (2000) SAS/STAT User's Guide Version 8. SAS Institute Inc., Cary, NC.

Sham P (1998) Statistics in Human Genetics. Arnold Publishers, London. Stallings MC, Cherny SS, Young SE, Miles DR, Hewitt JK, Fulker DW (1997) The familial aggregation of depressive symptoms, antisocial behavior, and alcohol abuse. Am J Med Genet (Neuropsych Genet) 74:183-191

StataCorp (2003) Stata Statistical Software Release 8.0. Stata Corporation, College Station, TX.

Truett KR, Eaves LJ, Walters EE, Heath AC, Hewitt JK, Meyer JM, Silberg J, Neale MC, Martin NG, Kendler KS (1994) A model system for analysis of family resemblance in extended kinships of twins. Behav Genet 24:35-49.

Van Eerdewegh P (1982) Statistical Selection in Multivariate Systems with Applications in Quantitative Genetics. Unpublished doctoral dissertation, Washington University, St. Louis, MO.

Vanyukov MM, Neale MC, Moss HB, Tarter RE (1996) Mating assortment and the liability to substance abuse. Drug Alcohol Depend 41: $1-10$. 
Vink JM, Willemsen G, Boomsma DI (2003) The association of current smoking behavior with the smoking behavior of parents, siblings, friends and spouses. Addiction 98:923-931.

World Health Organization (2001) The World Health Report, 2001. World Health Organization, Geneva, Switzerland.

World Health Organization (2003) The World Health Report, 2003. World Health Organization, Geneva, Switzerland.
Wright S (1921) Systems of mating III. Assortative mating based on somatic resemblance. Genetics 6:144-161.

Xian H, Scherrer JF, Eisen SA, True WR, Heath AC, Goldberg J, Lyons MJ, Tsuang MT (2000) Self-reported zygosity and the equal-environments assumption for psychiatric disorders in the Vietnam Era Twin Registry. Behav Genet 30:303-310. 